\title{
Soft-tissue sarcomas and exposure to chemical substances: a case-referent study
}

\author{
M ERIKSSON, ${ }^{1}$ L HARDELL, ${ }^{1} \mathrm{~N}$ O BERG,${ }^{2}$ T MÖLLER, ${ }^{3}$ AND O AXELSON ${ }^{4}$ \\ From the Department of Oncology, ${ }_{1}^{1}$ University Hospital, Umeå, Department of Pathology and Centre of \\ Oncology, ${ }^{3}$ University Hospital, Lund, and Department of Occupational Medicine, ${ }^{4}$ University Hospital, \\ Linköping, Sweden
}

ABSTRACT In 1977 several patients were seen with soft-tissue sarcomas and previous exposure to phenoxy acids. This clinical observation resulted in a case-referent (case-control) study being undertaken which showed that exposure to phenoxy acids or chlorophenols, which are chemically related, gave a roughly six-fold increase in the risk for this type of tumour. A further case-referent study of soft-tissue sarcomas has now been performed to confirm these earlier findings and also to obtain further information on the effects of different phenoxy acids. This new investigation gave an increase of the same magnitude in the risk for soft-tissue sarcomas after exposure to phenoxy acids or chlorophenols, but this risk related also to exposure to phenoxy acids free from impurities, such as polychlorinated dibenzodioxins and dibenzofurans.

Chemical pesticides have been used in agriculture and forestry in Sweden since the end of the 1940s. Whereas the consumption of insecticides has declined during the past 25 years and that of fungicides remained more or less constant, the use of herbicides has considerably increased.

Of the 4394 tons of active pesticides sold to agriculture in 1977,3776 tons $(86 \%)$ consisted of herbicides. Of the herbicides, the phenoxy acids amounted to 2690 tons $(71 \%)$. In addition to being present in most of the common agricultural herbicides, phenoxy acids are used in horticulture and in forestry to control unwanted hardwoods, as in the killing of individual trees by basal bark spraying, for example.

During the past few years, exposure to phenoxy acids has attracted an increasing interest as a possible cause of malignant disorders. There have been considerable difficulties, however, in ruling out the effect of concomitant pesticide exposure. Thus Swedish railroad workers were found to have an increased incidence of tumour and mortality related to exposure to both amitrol and phenoxy acid preparations, but there had been exposure to other compounds also. ${ }^{1-3}$ In E Germany a high incidence

Requests for reprints to: Dr L Hardell, Department of Oncology, University Hospital, S-901 85 Umeå, Sweden.

Received 19 March 1980

Accepted 1 May 1980 of lung cancer has been observed among pesticide workers, ${ }^{4}$ but again the exposure pattern was quite complex, the workers having been exposed not only to phenoxy acids like 2,4-dichlorophenoxyacetic acid (2,4-D) and 4-chloro-2-methyl-phenoxyacetic acid (MCPA), but also to lindane, various organic phosphorous insecticides, and some organic nitrocompounds.

Case reports on soft-tissue sarcomas ${ }^{5}$ and malignant lymphomas, ${ }^{6}$ as possibly related to exposure to phenoxy acids, have strengthened the suspicion that these preparations are carcinogenic. A recent casereferent (case-control) study has further underlined the probable aetiological relation between exposure to phenoxy acids or chlorophenols and soft-tissue sarcomas. ${ }^{7}$ Since both chlorophenols and 2,4,5-trichlorophenoxyacetic acid $(2,4,5-\mathrm{T})$ may contain polychlorinated dibenzodioxins and polychlorinated dibenzofurans, it remains possible that these impurities could be aetiologically responsible. This suggestion is supported somewhat by an observation from W Germany, where 75 persons were exposed to trichlorophenol and chlorinated dioxins in an accident in 1953. This group later developed an excess of neoplasms - that is, six malignant tumours observed against three to four expected. ${ }^{8}$ These data are not in any way conclusive. Some animal experiments indicate that chlorinated dioxins, ${ }^{8} 2,4,5-\mathrm{T},{ }^{9}$ and 
2,4,5-trichlorophenoxyethanol ${ }^{10}$ may all be carcinogenic.

The mutagenic properties of phenoxy acids have been investigated, with conflicting results: thus both positive ${ }^{11-14}$ and negative ${ }^{15-18}$ results have been reported. Inhibition of testicular DNA synthesis correlates with the carcinogenicity of chemicals. ${ }^{19}$ Testing five phenoxy acids (2,4-D, 2,4-dichlorophenoxy propionic acid (2,4-DP), 2,4,5-T, 2,4,5-Tester, MCPA, and 2-methyl-4-chlorophenoxy propionic acid (MCPP)) in such a system yielded positive results for four of them in that there was a significantly depressed thymidine uptake ${ }^{20}$; only 2,4-DP was not significantly positive.

Blood fat lowering drugs of the clofibrate type contain a phenoxy acid derivate (2-(4-chlorophenoxy)-2-methylpropionic acid ethyl-ester) and have been used to prevent ischaemic heart disease. There has been some concern regarding their possible carcinogenic effects since in a double-blind trial of 15745 healthy men assigned to three groups on the basis of their blood cholesterol concentrations there was an unequal distribution of cancer morbidity among the exposed and non-exposed individuals. ${ }^{21}$ In group I (high cholesterol) there were 106 malignancies in 5331 exposed individuals compared with 85 in 5296 untreated subjects in group II (high cholesterol); these two groups were similar in background variables. In the untreated low cholesterol and somewhat younger group III, there were 76 malignancies in 5118 individuals. The trial started in 1965 and ceased in 1976. It was designed to last for five years for each subject admitted but the follow-up lasted somewhat longer. This induction-latency time is short, and the interpretation of the data were somewhat obscured by an unclear idea of standardisation.

The use of 2,4,5-T was prohibited in Sweden in 1977 , and the phenoxy acids now available on the market are MCPA and 2,4-D and the analogous phenoxypropionic acids, mecoprop and dichloroprop. In comparison with $2,4,5-T$ these phenoxy acids are less prone to contain impurities in the form of polychlorinated dibenzodioxins and dibenzofurans.

Chlorophenols are mainly used to protect against blue stain and as impregnates in the saw mill industry, but are also used as wood preservatives in paints and tanneries and as proofing in clothes, etc.

To find out if the earlier findings of a relationship between exposure to phenoxy acids or chlorophenols and soft-tissue sarcomas could be confirmed, a new case-referent study of this type of tumour was undertaken. This time the investigation was performed in southern Sweden, to try to investigate the potential effects of MCPA, 2,4-D, and the analogous phenoxypropionic acids, all of which are widely used in the agricultural area of southern Sweden.

\section{Material and methods}

SUBJECT SELECTION

The study began in February 1979 and geographically encompassed the five southernmost counties of Sweden (Malmöhus, Kristianstad, Blekinge, Kronoberg, and Halland).

\section{Cases}

Cases were all patients with soft-tissue sarcomas that $\vec{\circ}$ had been diagnosed and reported to the cancer registry of the National Social Welfare Board in the years $\vec{\omega}$ 1974-8, and who lived in the afore-mentioned counties of Sweden at the time of diagnosis. Both living and dead patients were included in the study. All the tumour slides of the patients were scrutinised $\stackrel{\infty}{\infty}$ by two pathologists (Berg, Angervall), without prior $\vec{i}$ knowledge of whether they were exposed or unexposed. As a result of this procedure, 11 of the cases $\frac{\text { 의 }}{2}$ extracted from the cancer registry were omitted $\vec{T}$ because of a wrong or uncertain diagnosis.

\section{Referents}

For every case still alive in February 1979, eight potential referents, matched by municipality and age, $\vec{\varphi}$ were extracted from the National Population Regis- $\stackrel{\infty}{\longrightarrow}$ try. From these, the two individuals nearest in age to each living case were then used. One person with a serious brain injury and two who could not be located were excluded and replaced by other subjects from the pool of potential referents.

For each dead case, 10 referents matched by $\stackrel{\mathbb{Q}}{\not}$ municipality, age, and year of death were taken from $\overrightarrow{\overrightarrow{0}}$ the National Registry for Causes of Death to make 3 up a pool from which the dead referents were finally chosen. For those cases who had died in 1978, however, referents who died in 1977 were used for ethical $\bar{\Phi}$ reasons. People who had died from cancer were not 3 included as referents since a potential, primary re- $\overline{3}$ lation to exposure might be possible thus disqualifying cases of cancer among deceased individuals as $\hat{\rho}$ referents (cf Axelson ${ }^{23}$ ). For ethical reasons suicides were also excluded. Excluded individuals were re- 0 placed by the person nearest in age taken from the $>$ pool of referent candidates. A difference of more than five years in age between cases and referents was not accepted, and therefore it was necessary to ex- 0 tract 12 referents from neighbouring, socioecon- $N$ omically similar municipalities because of the small populations in some municipalities.

To avoid misleading results caused by the $\operatorname{dead}_{\infty}$

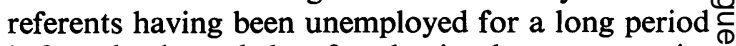
before death, and therefore having less opportunity $\stackrel{\oplus}{+}$ for exposure to various substances, sick leave and 0 retirement circumstances were checked through the $\stackrel{0}{0}$ records of the Public Health Insurance Offices. 
Referents were accepted only if they had been working until five years before the retirement or death of the cases. As a result of this criterion, 17 referents were lost but were replaced by other individuals from the candidate pool of dead referents. In addition, one dead immigrant referent, whose next-of-kin could not be located, was excluded and replaced again by the individual coming closest in age.

\section{ASSESSMENT OF EXPOSURE}

The people included in the investigation were, if possible, contacted in advance by telephone without the specific nature of the investigation being disclosed. Then they received by mail a nine-page questionnaire with various questions about previous and present occupation, different kinds of exposure in the working environment, smoking habits, and so on. Special emphasis on phenoxyacids or chlorophenols was thereby avoided. The replies were supplemented where necessary by a telephone interview; the interviewer not knowing whether the person interviewed was case or control (notice the benefit of using dead referentsfor dead cases). Particular attention was given to incomplete or obscure replies to questions about exposure to organic solvents or biocides. Furthermore, irrespective of the clarity of the replies in the questionnaires, all who had been working in agriculture, forestry, or horticulture during the period when biocides have been used in Sweden were interviewed, again blindly with regard to the subjects' status as case or referent. In this way a uniform assessment of exposure to biocides, and to other substances and work procedures of these categories, was obtained; within the trades of forestry, farming, and horticulture exposure was particularly well assessed. Three cases and two referents had to be interviewed by letter since they were not on the telephone. Of these, one case had been employed in agriculture for some time. None of these cases or referents was exposed to phenoxy acids or chlorophenols. The data concerning deceased individuals were obtained by contact with the next-of-kin defined in the order of wife, child, parent, sibling, or other. If judged necessary the interviewer also contacted employers, boards of agriculture, machine pools, neighbours, and others to elucidate possible exposure among the deceased. This was also carried out without knowing whether those investigated were cases or referents.

\section{Special aspects on exposure}

Individuals who had not personally participated in spraying but had relied instead on machine pools or other workers were considered in a separate analysis to find out if work on such a farm aggravated the risk of the type of tumour under study. The embank- ments of Swedish State Railways have been sprayed mainly with amitrol, but pesticides including phenoxy acids have also been used. It was not possible to determine completely all the substances to which individuals had been exposed, despite contact with the people themselves, their workmates, or their employers. Therefore, railway workers who reported exposure to pesticides were regarded as unexposed to phenoxy acids. This applied, however, to one case and one referent only.

Exposure to chlorophenols might have occurred in those having contact with cutting oils and employees in the shoe and leather industries, but because of the difficulty in specifying such exposure, these groups were regarded as unexposed, making the study conservative. One subject employed in a tannery, on the other hand, was judged to be exposed to chlorophenols because of the manifest exposure often inherent in such activity.

The investigation also included inquiries about blood fat lowering drugs of the clofibrate type; case records were checked when there was any doubt. Since none of the subjects satisfied the latency criterion defined below, no analysis of the material in this respect was carried out.

CONSIDERATIONS IN THE DATA ANALYSIS Low-grade exposure to phenoxy acids, defined as exposure shorter than a total of one day, has not been considered as exposure in this study. Concerning wood preservatives containing chlorophenols, a separate analysis was made regarding low-grade exposure, defined as a maximum of one continuous week or repeated periods of short-term exposure amounting at the most to one month in all.

The latency period for the chemical induction of solid malignant tumours in man is generally considered to be in the range of $15-30$ years. ${ }^{24}$ Thus recent exposure to phenoxy acids and chlorophenols-that is, exposure within five years before the year of diagnosis for the case-was excluded for both cases and referents.

The data were also analysed with regard to exposure to other agents-for instance, organic solvents, DDT, and mercurial seed dressing-since there could be a confounding effect in this context of simultaneous or consecutive occupational exposures, provided that work with these compounds might constitute risk factors for the relevant morbidity (cf Axelson ${ }^{225}$ ).

Furthermore, it must be pointed out that detailed knowledge of dispersing agents is lacking, and that the concept of exposure therefore refers to the handling of the various commercial preparations although designated by the name of the active substance. 
Table 1 Histopathological diagnoses in the reviewed material

\begin{tabular}{|c|c|c|c|}
\hline Diagnosis & No of cases & Diagnosis & No of cases \\
\hline Leiomyosarcoma & 33 & Dermatofibrosarcoma & 3 \\
\hline Malignant fibrous histiocytoma & 19 & Atypical fibroxanthoma & 2 \\
\hline Liposarcoma & 15 & Synovial sarcoma & 2 \\
\hline Neurogenic sarcoma & 11 & Sarcoma NUD & 2 \\
\hline Angiosarcoma & 9 & Ewing's sarcoma (extraskeletal) & 1 \\
\hline Myxofibrosarcoma & 7 & Rhabdomyosarcoma & 1 \\
\hline Fibrosarcoma & 5 & Total & 110 \\
\hline
\end{tabular}

Table 2 Exposure to phenoxy acids or chlorophenols in triplets (one case and two referents)

\begin{tabular}{llll}
\hline $\begin{array}{l}\text { Cases with exposure to } \\
\text { phenoxy acids or chlorophenols }\end{array}$ & $\begin{array}{l}\text { No of referents in the triplet } \\
\text { with exposure to phenoxy acids or } \\
\text { chlorophenols }\end{array}$ \\
\hline & 2 & 1 & 0 \\
\cline { 2 - 3 } Yes & 0 & 4 & 21 \\
No & 0 & 9 & 76 \\
\hline
\end{tabular}

$x^{2}(1)=20 \cdot 1$.

Risk ratio: Point estimate: $5 \cdot 1 ; 95 \%$ confidence interval : $2 \cdot 5 \cdot 10 \cdot 4$.

\section{STATISTICAL METHODS}

Calculations of $\chi^{2}$-values and risk ratios, taken as the odds ratios, in the matched material were based on principles stipulated by Miettinen. ${ }^{26}{ }^{27}$ The effect of sustained versus dissolved matching was evaluated as the quotient of the risk ratios in the unmatched to the matched material ( $\mathrm{cf}$ Miettinen ${ }^{28}$ ). A test-based approximative method ${ }^{29}$ was used to calculate confidence intervals of the risk ratios.

\section{Results}

Included in the study were 330 subjects, 110 cases (38 dead), and 220 referents. Table 1 shows the histopathological classification of the cases. The shortfall consisted of one referent $(0.3 \%)$, regarded as unexposed for the calculations with sustained matching and excluded after dissolving the matching. Exposure to phenoxy acids or chlorophenols was reported by $25(22.7 \%)$ of the cases and $13(5.9 \%)$ of the controls. One case and one control with less than one day of exposure were judged unexposed (work in own gardens), as indicated above.
Table 4 Exposure to phenoxy acids. Cases and referents with exposure to chlorophenols are excluded

\begin{tabular}{llll}
\hline & \multicolumn{2}{c}{ Exposed } & Unexposed \\
\cline { 2 - 4 } & $>30$ days & $\leq 30$ days & \\
\hline Cases & 7 & 7 & 85 \\
Referents & 2 & 3 & 206 \\
Risk ratio & 8.5 & $5 \cdot 7$ & $(1 \cdot 0)$ \\
\hline
\end{tabular}

The risk ratio (odds ratio) for soft-tissue sarcomas after exposure to phenoxy acids or chlorophenols was found to be $5 \cdot 1$ (table 2) in the matched material and 4.7 after dissolving the matching. These risk ratios indicated that the matching factors rather masked the risk, and therefore dissolving of the matching seemed acceptable for the further analyses, simplifying the calculations and making the study somewhat conservative.

\section{PHENOXY ACIDS}

The effect of exposure to phenoxy acids alone was analysed as part of the study. The risk ratio of exposure to phenoxy acids amounted to $6 \cdot 8$ (table 3 ), and an exposure-effect relation was indicated in the division of the material according to duration of exposure, but the trend was not significant (table 4).

The risk ratio relating to the exposure to phenoxy acids taken as free from polychlorinated dibenzodioxins and dibenzofurans - that is, MCPA, 2,4-D, mecoprop, dichlorprop-amounted to $4 \cdot 2$ (table 3 ).

Eight cases $(7 \cdot 3 \%)$ and 17 referents $(7 \cdot 8 \%)$ reported ownership of, or employment on, farms where chemical pesticides were sprayed by machinery pool stations or by someone else without their own

Table 3 Exposure to different phenoxy acids or chlorophenols among cases and controls after dissolving the matching

\begin{tabular}{|c|c|c|c|c|c|}
\hline & \multirow{2}{*}{$\begin{array}{l}\text { Non-exposed both } \\
\text { to phenoxy acids and } \\
\text { to chlorophenols }\end{array}$} & \multicolumn{4}{|l|}{ Exposed } \\
\hline & & $\begin{array}{l}\text { Non } 2,4,5-T \\
\text { phenoxy acids }\end{array}$ & $\begin{array}{l}2,4,5-T \text { and } \\
\text { other phenoxy } \\
\text { acids }\end{array}$ & $\begin{array}{l}\text { Total } \\
\text { exposed to } \\
\text { phenoxy acids }\end{array}$ & Chlorophenols \\
\hline Cases & 85 & 7 & 7 & 14 & 11 \\
\hline Referents & 206 & 4 & 1 & 5 & 8 \\
\hline $\begin{array}{l}\text { Risk ratio: } \\
\text { Point estimate } \\
95 \% \text { confidence interval }\end{array}$ & $1 \cdot 0$ & $4 \cdot 2$ & $17 \cdot 0$ & $\begin{array}{l}6 \cdot 8 \\
2 \cdot 6-17 \cdot 3\end{array}$ & $\begin{array}{l}3 \cdot 3 \\
1 \cdot 3-8 \cdot 1\end{array}$ \\
\hline
\end{tabular}


active participation. Thus an increased risk was not shown, nor was there any substantial tendency towards a lower risk ratio than expected.

\section{CHLOROPHENOLS}

The exposure to chlorophenols resulted in a risk ratio of 3.3 (table 3). Low-grade exposure, as defined above, was present among $7 \cdot 3 \%$ of the cases and $5.5 \%$ of referents, and thus did not seem to constitute a hazard.

\section{OTHER EXPOSURES}

The relative risk due to exposure to organic solvents was also analysed. High- and low-grade exposures were defined with the same time criteria as applied to chlorophenol exposure (see above), which resulted in a relative risk of 1.6 for high- and 1.9 for lowgrade exposure, both with $90 \%$ confidence intervals encompassing $1 \cdot 0$. The questionnaire also included a survey of exposure to various other substances and materials (table 5).

Information about asbestos, glass fibre, and power

Table 5 Frequency of exposure in \% to different agents in total sample or 110 cases and 219 referents and in 95 cases and 212 referents after exclusion of individuals also exposed to phenoxy acids or chlorophenols. (For exposure to phenoxy acids or chlorophenols see other tables)

\begin{tabular}{|c|c|c|}
\hline \multirow[b]{2}{*}{-} & \multicolumn{2}{|c|}{ Exposure frequency, $\%$} \\
\hline & Cases & Referents \\
\hline \multicolumn{3}{|l|}{ Agents } \\
\hline Total no of subjects & $(110)$ & $(219)$ \\
\hline Asbestos & $4 \cdot 5$ & $3 \cdot 7$ \\
\hline Glass fibre & $7 \cdot 3$ & $3 \cdot 7$ \\
\hline Power saw & $8 \cdot 2$ & $5 \cdot 5$ \\
\hline Smoking, now and previously & $71 \cdot \overline{8}$ & $70 \cdot 3$ \\
\hline \multicolumn{3}{|l|}{ Pesticides } \\
\hline Total* & $21 \cdot 8$ & $11 \cdot 0$ \\
\hline Amitrole & 0.9 & 0.5 \\
\hline Bromofos & $1 \cdot 8$ & 0.9 \\
\hline DDT & $6 \cdot 4$ & $5 \cdot 0$ \\
\hline Dinoseb & $2 \cdot 7$ & 0.9 \\
\hline Fenitrotion & 0.9 & 0.5 \\
\hline Mercurial seed dressing & $8 \cdot 2$ & $4 \cdot 6$ \\
\hline Lindane & $0 \cdot 9$ & 0.5 \\
\hline Sodium chlorate & 0.9 & 0.9 \\
\hline Nicotine & $2 \cdot 7$ & 0.5 \\
\hline Other $\dagger$ & $13 \cdot 6$ & $6 \cdot 8$ \\
\hline \multicolumn{3}{|l|}{ No of subjects after exclusion } \\
\hline phenoxy acids or chorophenols & $(95)$ & $(212)$ \\
\hline \multicolumn{3}{|l|}{ Pesticides } \\
\hline Total* & $9 \cdot 5$ & $8 \cdot 0$ \\
\hline \multicolumn{3}{|c|}{$\begin{array}{l}\text { * Percentage of individuals exposed to one or more pesticides (other } \\
\text { than phenoxy acids or chlorophenols). } \\
\text { tRefers to more rarely occurring pesticides to which either cases or } \\
\text { referents were found not to have been exposed (at most two subjects of } \\
\text { each group appear when the other is not represented) and unknown } \\
\text { substances (four cases and six referents); altogether } 15 \text { substances } \\
\text { were named in this group. }\end{array}$} \\
\hline
\end{tabular}

saws are more uncertain than for other types of exposure, since these assessments of exposure were based entirely on the questionnaires without telephone interviews to supplement obscure data. The risk ratios relating to exposure to DDT, mercurial seed dressing, etc, according to table 5 could not be regarded as raised since the $90 \%$ confidence intervals for the risk ratios included unity.

\section{Discussion}

This investigation was prompted by an earlier demonstration of an association between soft-tissue sarcomas and exposure to phenoxy acids or chlorophenols. The aim of this new study was partly to see whether the results of the earlier investigation could be reproduced in another area, and partly to elucidate whether exposure to phenoxy acids not contaminated by polychlorinated dibenzodioxins and dibenzofurans that are commonly used in agriculture, may also constitute a hazard with regard to this particular group of tumours.

Regarding methods, the investigation was similar to the earlier study. Dead individuals were selected as referents for dead cases to create similar conditions for the assessment of exposure. As indicated above, however, people dying from a malignant tumour were not included among the referents, since possible carcinogenicity of the studied exposures would perhaps also lead to mortality from various other malignancies; then the exposure frequency would have been falsely increased among the referents. This restriction did not apply to living referents whose cancer morbidity was not investigated. Interestingly, one living referent with massive exposure to MCPA spontaneously reported that he was undergoing treatment for a malignant tumour.

Since industry and agriculture are structured differently in southern Sweden the questionnaire devised for the present investigation was slightly modified from that used in the study in northern Sweden. In both studies many questions relevant to various aspects of working life were included to conceal the purpose of the investigation, and supplementary interviews were performed blind concerning the individual's status of case or referent. In view of the accuracy of the observation of exposure it might be recalled that those using machinery pools stations showed almost the same exposure frequency irrespective of status as case or referent. Also the exposure was similar to other agents, which is of considerable interest, particularly for asbestos, since there had been an intense debate about the carcinogenic hazards of asbestos work and a country-wide health check-up was going on for individuals exposed to asbestos. These circumstances do not seem to have 
influenced the reporting of exposure in this regard (table 5).

\section{CONFOUNDING FACTORS}

Potential confounding problems relating to age, place of residence, and year of death were avoided by restricting the material and by matching. Exposure to chemical pesticides other than phenoxy acids may be judged risk factors for the morbidity under study, and might exert a confounding effect, since the individuals using phenoxy acids were often also in contact with other agents used to combat weeds, insects, or fungi. Thus a co-variation in exposure tends to prevail, which means that the effect of the simultaneous or consecutive exposures to different pesticides cannot be definitely evaluated in all respects. The same applies to carrier agents and possible contaminants. Substances other than phenoxy acids that were used in agriculture, forestry, and horticulture could often be named by the subjects in this study, as is indicated in table 5.

Some over-representation of exposure even to pesticides other than phenoxy acids was observed among the cases. Exclusion of individuals who reported simultaneous exposure to phenoxy acids, however, left $9.5 \%$ of the cases and $8.0 \%$ of the controls who were exposed to several of these other pesticides, which do not apparently exert a demonstrable effect. Risk calculations for specific chemical pesticides other than phenoxy acids were not considered to be useful because of the paucity of exposed subjects. The same appears to be true for exposure to chlorophenols, glass fibre, and asbestos, where again, having excluded chlorophenol exposure, there was little difference between cases and referents.

In the assessment of exposure via questionnaires and interviews there is the possibility that the cases take more interest in the questions than the referents. To elucidate a possible distortion of this kind, the material was also analysed with regard to exposure to phenoxy acids among the cases and referents employed in agriculture or forestry. As mentioned above all the replies in the questionnaires of those cases and referents who had been working in agriculture or forestry were supplemented over the telephone to achieve the best possible estimation of exposure. For exposed individuals in agriculture and forestry a relative risk of 6.4 was obtained by comparison with other occupations without exposure, whereas nonexposed individuals within agriculture and forestry presented a relative risk of $1 \cdot 1$ (table 6 ).

If the exposure of the cases was considerably exaggerated and that of the referents highly underestimated, a value far below 1.0 would have been obtained in the calculation of the risk ratio of the unexposed individuals in agriculture and forestry, as compared with other occupations outside this domain. This phenomenon would have occurred with a high risk ratio among the exposed and a reasonably high exposure frequency among the individuals occupied in forestry, farming, and horticulture. ${ }^{30}$ The obtained risk ratio of 1.1 indicates that any substantial distortion in the observation of exposure to phenoxy acids could hardly be present in the study.

In summary this investigation has indicated that exposure to phenoxy acids and chlorophenols might constitute a risk factor in the development of softtissue sarcomas, and that the risk relates not only to 2,4,5-trichlorophenoxy acids which, like certain chlorophenols, may contain polychlorinated dibenzodioxins and dibenzofurans, hut also to other phenoxy acids.

This investigation was made possible by grants from the Swedish National Board of Occupational Safety and Health. The authors are especially grateful to Professor Lars-Gunnar Larsson, Umeå, for his help in the methodological work and to Professor Lennart Angervall, Göteborg, for his co-operation on the review of the histological specimens. We also thank Dr Margareta Simonsson for her help with the interviews and Ms Monika Andersson for her editorial help.

\section{References}

${ }^{1}$ Axelson O, Sundell L. Herbicide exposure, mortality and tumour incidence. An epidemiological investigation on Swedish railroad workers. Scand J Work Environ Health $1974 ; 11: 21-8$.

${ }^{2}$ Axelson O. Aspects of confounding in occupational health epidemiology. Scand J Work Environ Health 1978;4: 98-102.

${ }^{3}$ Axelson O, Sundell L, Andersson K, Edling C, Hogstedt C, Kling $\mathrm{H}$. Herbicide exposure and tumour mortality; an

Table 6 Exposure to phenoxy acids in cases and referents by occupation

\begin{tabular}{|c|c|c|c|c|c|c|}
\hline & \multicolumn{3}{|c|}{ Agriculture/forestry } & \multicolumn{3}{|c|}{ Other occupations } \\
\hline & Phenoxy acids & Chlorophenols & Unexposed & Phenoxy acids & Chlorophenols & Unexposed \\
\hline Cases & 13 & 1 & 17 & 1 & 10 & 68 \\
\hline Referents & 5 & 3 & 39 & 0 & 5 & 167 \\
\hline Risk ratio & $6 \cdot 4$ & - & $1 \cdot 1$ & - & - & $(1 \cdot 0)$ \\
\hline
\end{tabular}


update epidemiological investigation on Swedish railroad workers. Scand J Work Environ Health 1980;6:73-9.

${ }^{4}$ Barthel E. Gehäufes Vorkommen von Bronchialkrebs bei beruflicher Pestizidexposition in der Landwirschaft. Erkr Atmungsorgane 1976;146:266-74.

${ }^{5}$ Hardell L. Soft tissue sarcomas and exposure to phenoxyacetic acids - a clinical observation. Läkartidningen 1977; 74:2753-4.

${ }^{6}$ Hardell L. Malignant lymphoma of histiocytic type and exposure to phenoxyacetic acids or chlorophenols. Lancet 1979 ; i:55-6.

${ }^{7}$ Hardell L, Sandström A. Case-control study: soft-tissue sarcomas and exposure to phenoxyacetic acids or chlorophenols. Br J Cancer 1979;39:711-7.

${ }^{8}$ Tóth K, Sugár J, Somfai-Relle S, Bence J. Carcinogenic bioassay of the herbicide 2,4,5-trichlorophenoxyethanol (TCPE) with different 2,3,7,8-tetrachlorodibenzo-pdioxin (dioxin) content in Swiss mice. Prog Biochem Pharmacol 1987;14:82-93.

9 Muranyi-Kovacs I, Rudali G, Imbert J. Bioassay of 2,4,5trichlorophenoxyacetic acid for carcinogenicity in mice. Br J Cancer 1976;33:626-33.

${ }^{10}$ Tóth K, Somfai-Relle S, Sugár J, Bence J. Carcinogenicity testing of herbicide 2,4,5-trichlorophenoxyethanol containing dioxin and of pure dioxin in Swiss mice. Nature 1979;278:548-9.

11 Dävring HL, Hultgren K. Cytogenic effects on in-vivo bone marrow cells of mice musculus induced by a commercial 2,4,5-T ester product. Hereditas 1977;85:123-34.

12 Majumdar SK, Golia JK. Mutation test of 2,4,5-trichlorophenoxyacetic acid on Drosophila melanogaster. Can J Genet Cytol 1974;16:465-6.

${ }^{13}$ Vogel E, Chandler JLR. Mutagenicity testing of cyclamate and some pesticides in Drosophila melanogaster. Experientia 1974;30:621-3.

14 Zetterberg G, Busk L, Elovson R, Starec-Nordenhammar I, Ryttmann $\mathrm{H}$. The influence of $\mathrm{pH}$ on the effects of 2,4-D (2,4-dichlorophenoxyacetic acid, Na salt) on Saccharomyces cerevisiae and Salmonella typimurium. Mutat Res 1977;42:3-18.

15 Andersen KJ, Leighty EG, Takahashi MT. Evaluation of herbicides for possible mutagenic properties, J Agric Food Chem 1972;20:649-56.
${ }^{16}$ Epstein SS, Arnold E, Andrea J, Bass W, Bishop Y. Detection of chemical mutagens by the dominant lethal assay in the mouse. Toxicol Appl Pharmacol 1972;23:288-325.

${ }^{17}$ Fahrig R. Comparative mutagenicity studies with pesticides. IARC Sci Publ No 10. 1974;161-81.

18 Jenssen D, Renberg L. Distribution and cytogenetic test of 2,4-D and 2,4,5-T phenoxyacetic acids in mouse blood tissues. Chem Biol Interact 1976;14:291-9.

19 Seiler JP. The genetic toxicology of phenoxy acids other than 2,4,5-T. Mutat Res 1978;55:197-226.

${ }^{20}$ Seiler JP. Phenoxyacids as inhibitors of testicular DNA synthesis in male mice. Bull Environ Contam Toxicol $1979 ; 21: 89-92$.

${ }^{21}$ Oliver MF, Heady JA, Morris JN, Cooper J. A co-operative trial in the primary prevention of ischemic heart disease using clofibrate. Br Heart $J$ 1978;40:1069-118.

${ }^{22}$ Norstrom A, Rappe C, Lindahl R, Buser HR. Analysis of some older Scandinavian formulations of 2,4-D (2,4dichlorophenoxyacetic acid) and 2,4,5-T (2,4,5-trichlorophenoxyacetic acid) for contents of chlorinated dibenzodioxins and dibenzofurans. Scand J Work Environ Health 1980;5:375-8.

${ }^{23}$ Axelson O. The case-referent (case-control) study in occupational health epidemiology. Scand $J$ Work Environ Health 1979;5:91-9.

${ }^{24}$ Hueper WC, Conway WD. Chemical carcinogenesis and cancers. Springfield: Thomas, 1964.

${ }^{25}$ Axelson O. Aspects on confounding and effect-modification in the assessment of occupational cancer risk. J Toxicol Environ Health (in press).

${ }^{26}$ Miettinen OS. Individual matching with multiple controls in the case of all-or-none response. Biometrics 1969;25: 339-55.

${ }^{27}$ Miettinen OS. Estimation of relative risk from individually matched series. Biometrics 1970;26:75-86.

${ }^{28}$ Miettinen OS. Components of the crude risk ratio. Am J Epidemiol 1972;96:168-72.

29 Miettinen OS. Estimability and estimation in case-referent studies. Am J Epidemiol 1976;103:226-35.

30 Axelson $\mathbf{O}$. A note on observational bias in case-referent studies in occupational health epidemiology. Scand $J$ Work Environ Health 1980;6:80-2. 